\title{
Squamosamide Derivative FLZ Protects Retinal Pigment Epithelium Cells from Oxidative Stress through Activation of Epidermal Growth Factor Receptor (EGFR)-AKT Signaling
}

\author{
Li-Bo Cheng ${ }^{\dagger}, *$, Chun-Ming Chen ${ }^{\dagger}$, Hong Zhong and Li-Juan Zhu * \\ Eye Department, Li-yang City Hospital of Traditional Chinese Medicine, Li-Yang City 213300, China; \\ E-Mails: chunmingchenapp@163.com (C.-M.C.); hongapple126@126.com (H.Z.)
}

$\dagger$ These authors contributed equally to this work.

* Authors to whom correspondence should be addressed;

E-Mails: dryaojin@yahoo.com (L.-B.C.); caocong1111@hotmail.com (L.-J.Z.);

Tel./Fax: +86-25-8667-7699 (L.-B.C.); +86-512-6588-3602 (L.-J.Z.).

External Editor: Anthony Lemarié

Received: 3 June 2014; in revised form: 2 September 2014 / Accepted: 11 September 2014 /

Published: 17 October 2014

\begin{abstract}
Reactive oxygen species (ROS)-mediated retinal pigment epithelium (RPE) cell apoptosis is attributed to age-related macular degeneration (AMD) pathogenesis. FLZ, a novel synthetic squamosamide derivative from a Chinese herb, Annona glabra, has displayed significant cyto-protective activity. In the current study, we explored the pro-survival effect of FLZ in oxidative stressed-RPE cells and studied the underlying signaling mechanisms. Our results showed that FLZ attenuated hydrogen peroxide $\left(\mathrm{H}_{2} \mathrm{O}_{2}\right)$-induced viability decrease and apoptosis in the RPE cell line (ARPE-19 cells) and in primary mouse RPE cells. Western blotting results showed that FLZ activated AKT signaling in RPE cells. The AKT-specific inhibitor, MK-2206, the phosphoinositide 3-kinase (PI3K)/AKT pan inhibitor, wortmannin, and AKT1-shRNA (short hairpin RNA) depletion almost abolished FLZ-mediated pro-survival/anti-apoptosis activity. We discovered that epidermal growth factor receptor (EGFR) trans-activation mediated FLZ-induced AKT activation and the pro-survival effect in RPE cells, and the anti-apoptosis effect of FLZ against $\mathrm{H}_{2} \mathrm{O}_{2}$ was inhibited by the EGFR inhibitor, PD153035, or by EGFR shRNA-knockdown. In conclusion, FLZ protects RPE cells from oxidative stress through activation of EGFR-AKT signaling, and our results suggest that FLZ might have therapeutic values for AMD.
\end{abstract}


Keywords: age-related macular degeneration (AMD); retinal pigment epithelium (RPE); squamosamide derivative FLZ; apoptosis; AKT signaling and EGFR (epidermal growth factor receptor) trans-activation

\section{Introduction}

Age-related macular degeneration (AMD) is a progressive retinal degeneration disease, which causes blindness among elderly people [1]. Ultraviolet (UV) exposure and reactive oxygen species (ROS) damage are the main pathological causes of AMD [2,3]. Under oxidative stress, reactive free radicals, including superoxide, hydroxyl radical, singlet oxygen and hydrogen peroxide $\left(\mathrm{H}_{2} \mathrm{O}_{2}\right)$, induce damage to retinal pigment epithelium (RPE) cells by excessively oxidizing key cellular components [2,3]. Anti-oxidants or zinc-containing supplements could reduce AMD progression in human [4,5]. Thus, oxidative stress prevention is an effective strategy to slow down or even reverse AMD progression. Groups including ours have been adding $\mathrm{H}_{2} \mathrm{O}_{2}$ to cultured RPE cells to create a cellular model of AMD and to explore the potential interfering strategies [6-10].

FLZ (chemical name $N$-[2-(4-hydroxy-phenyl)-ethyl]-2-(2,5-dimethoxy-phenyl)-3-(3-metho xy-4-hydroxy-phenyl)-acrylamide) is a synthetic novel derivative of squamosamide found in the Chinese herb, Annona glabra [11-16]. Studies have shown that FLZ displayed a significant neuroprotective effect both in vivo and in vitro [11-16]. Further, FLZ exerted dramatic myocardial protection activity [14,17]. The underling mechanism of the FLZ-induced cytoprotective effect has not yet been fully understood, although AKT activation has been proposed [11,13]. AKT plays a vital role in cell survival [18]. AKT regulates multiple downstream targets to prevent cell apoptosis [18]. Activated AKT suppresses apoptosis by phosphorylating and inactivating the pro-apoptotic proteins (i.e., Bad and caspase 9). Further, AKT activates nuclear factor-kappa B (NF-kB) to inhibit cell apoptosis $[19,20]$. Our previous study demonstrated that nerve growth factor (NGF) and $\alpha$-melanocyte stimulating hormone ( $\alpha-\mathrm{MSH})$ rescued oxidative stressed-RPE cells by activating AKT signaling [6].

In light of this information, we proposed that FLZ might exert a protective effect against oxidative stress in RPE cells. We thus explored the potential role of FLZ on $\mathrm{H}_{2} \mathrm{O}_{2}$-treated RPE cells. We identified a new FLZ-mediated pro-survival pathway that attenuated $\mathrm{H}_{2} \mathrm{O}_{2}$-induced RPE cell damage and that may minimize the risk of developing AMD.

\section{Results and Discussion}

\subsection{FLZ Protects Retinal Pigment Epithelium (RPE) Cells from Hydrogen Peroxide $\left(\mathrm{H}_{2} \mathrm{O}_{2}\right)$}

In the current study, we aimed to understand the potential role of FLZ against oxidative stress in RPE cells. MTT (3-(4,5-dimethyl-2-thiazolyl)-2,5-diphenyl-2-H-tetrazolium bromide) cell viability results in Figure 1A demonstrated that FLZ $(0.1-25 \mu \mathrm{M})$ alone had no detectable effect on APRE-19 (a human RPE cell line) survival ( $p>0.05 v s$. untreated control group). Significantly, FLZ at doses of 1-25 $\mu \mathrm{M}$ attenuated $\mathrm{H}_{2} \mathrm{O}_{2}$-induced APRE-19 cell viability decrease (Figure 1B,C). Further, in primary cultured RPE cells, FLZ $(1 \mu \mathrm{M})$ also inhibited $\mathrm{H}_{2} \mathrm{O}_{2}$-induced cell viability reduction (Figure 1D). FLZ showed 
the most significant cyto-protective activity when $\mathrm{H}_{2} \mathrm{O}_{2}$ was at a concentration of $400 \mu \mathrm{M}$, and this concentration was chosen for further experiments. Thus, these results show that FLZ protects RPE cells against $\mathrm{H}_{2} \mathrm{O}_{2}$.

Figure 1. FLZ protects RPE (retinal pigment epithelium) cells from hydrogen peroxide $\left(\mathrm{H}_{2} \mathrm{O}_{2}\right)$. The cell viability of APRE-19 cells with the indicated $\mathrm{H}_{2} \mathrm{O}_{2}$ or plus FLZ treatment for $24 \mathrm{~h}$ was tested by the MTT (3-(4,5-dimethyl-2-thiazolyl)-2,5-diphenyl-2-H-tetrazolium bromide) assay (A-C); Primary cultured mouse RPE cells were treated with $\mathrm{H}_{2} \mathrm{O}_{2}$ (200-600 $\mu \mathrm{M})$ with or without FLZ $(1 \mu \mathrm{M})$ for $24 \mathrm{~h}$; cell viability was tested by the MTT assay (D). Experiments were repeated three times to ensure the consistency of the results. "C" stands for the untreated control group. "Ctrl" stands for no $\mathrm{H}_{2} \mathrm{O}_{2}$. Vehicle stands for $0.1 \%$ dimethyl sulfoxide (DMSO). ${ }^{*} p<0.05$ (Analysis of Variance, ANOVA).

A.

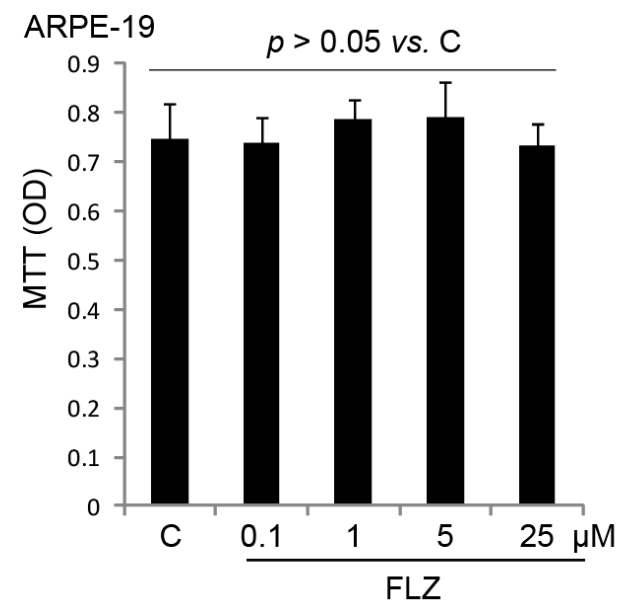

C.

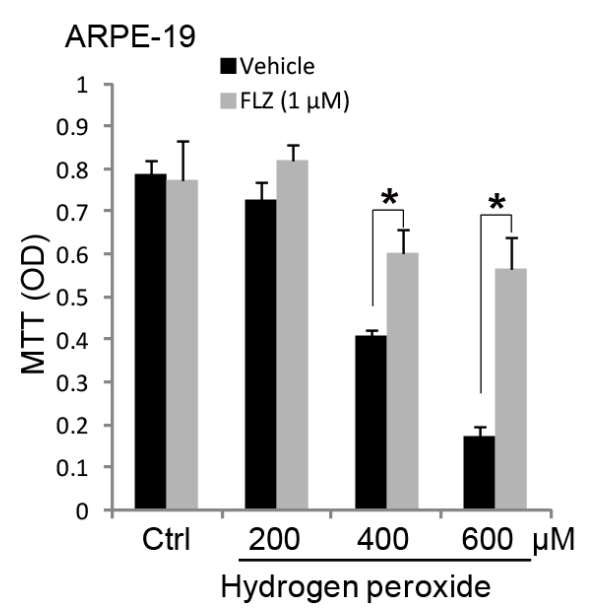

B.

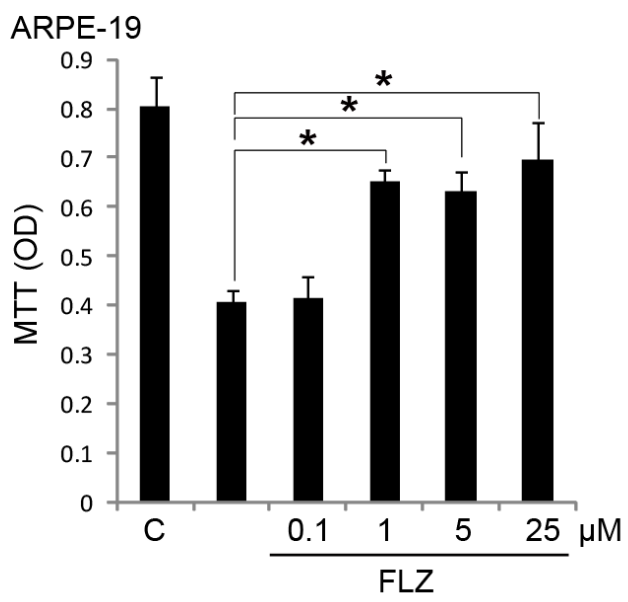

D.

Hydrogen peroxide $(400 \mu \mathrm{M})$

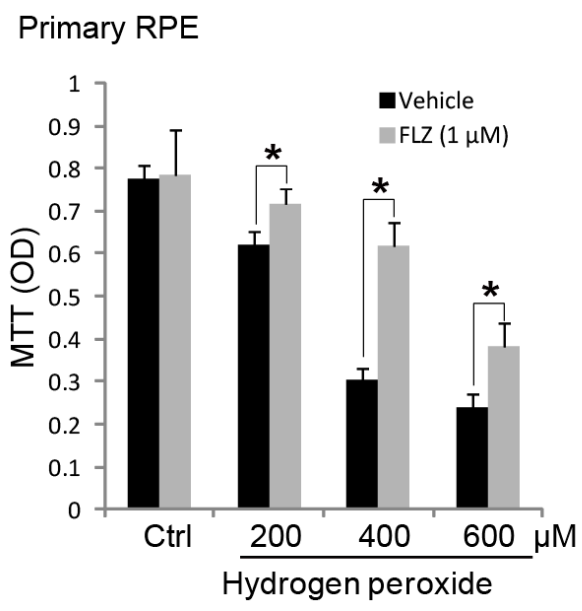

\subsection{FLZ Attenuates $\mathrm{H}_{2} \mathrm{O}_{2}$-Induced RPE Cell Apoptosis}

Next, we tested the role of FLZ on RPE cell apoptosis induced by $\mathrm{H}_{2} \mathrm{O}_{2}$. RPE cell apoptosis was tested by the Annexin-V FACS assay and the terminal deoxynucleotidyl transferase dUTP nick end labeling (TUNEL) staining assay [8,21]. In APRE-19 cells, apoptosis was induced by $\mathrm{H}_{2} \mathrm{O}_{2}$ (Figure 2A,B,D). Co-treatment with FLZ $(1 \mu \mathrm{M})$ significantly inhibited $\mathrm{H}_{2} \mathrm{O}_{2}$-induced APRE-19 cell 
apoptosis (Figure 2A,B,D). Interestingly, we noticed a proportion of necrotic APRE-19 cells (Annexin- $\mathrm{V}^{-1-}$ and $\mathrm{PI}^{+/+}$cells) after $\mathrm{H}_{2} \mathrm{O}_{2}$ stimulation, which was also inhibited by FLZ co-treatment (Figure 2A,C). In primary RPE cells, $\mathrm{H}_{2} \mathrm{O}_{2}$-induced apoptosis was again alleviated by FLZ (Figure 2E). Together, these results demonstrate that FLZ attenuates $\mathrm{H}_{2} \mathrm{O}_{2}$-induced RPE cell apoptosis.

Figure 2. FLZ attenuates $\mathrm{H}_{2} \mathrm{O}_{2}$-induced RPE cell apoptosis. Annexin-V/PI FACS images of APRE-19 cells treated with $\mathrm{H}_{2} \mathrm{O}_{2}(400 \mu \mathrm{M})$ or plus FLZ $(1 \mu \mathrm{M})$ for $24 \mathrm{~h}(\mathbf{A})$; results were quantified in (B,C); APRE-19 cells $(\mathbf{D})$ and primary mouse RPE cells $(\mathbf{E})$ were treated with the indicated concentration of $\mathrm{H}_{2} \mathrm{O}_{2}$ or plus FLZ $(1 \mu \mathrm{M})$ for $24 \mathrm{~h}$, and cell apoptosis was analyzed by the terminal deoxynucleotidyl transferase dUTP nick end labeling (TUNEL) staining assay. Experiments were repeated three times to ensure the consistency of the results. "C" stands for the untreated control group. Vehicle stands for $0.1 \%$ DMSO. $* p<0.05$ (ANOVA).

A.

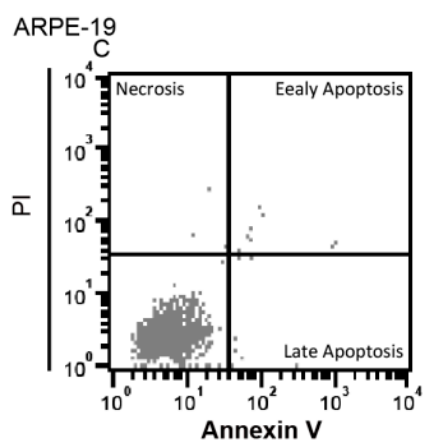

B.

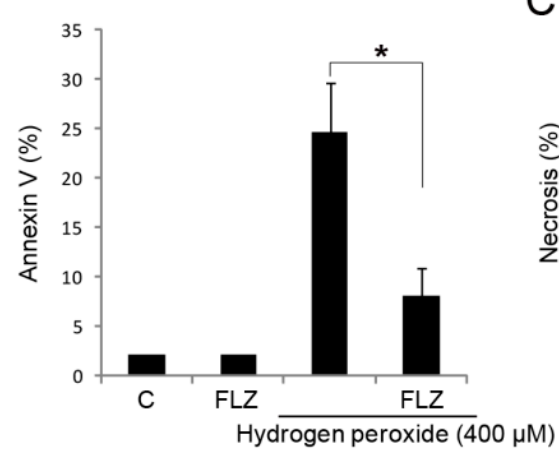

C
Hydrogen peroxide $(400 \mu \mathrm{M})$ Hydrogen peroxide + FLZ
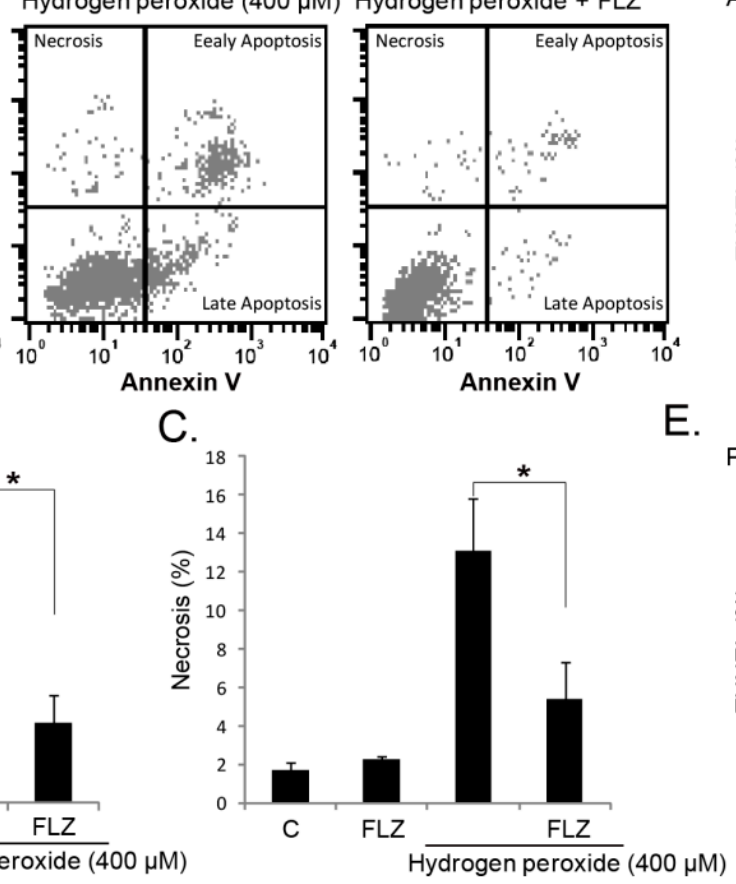

E.
D.
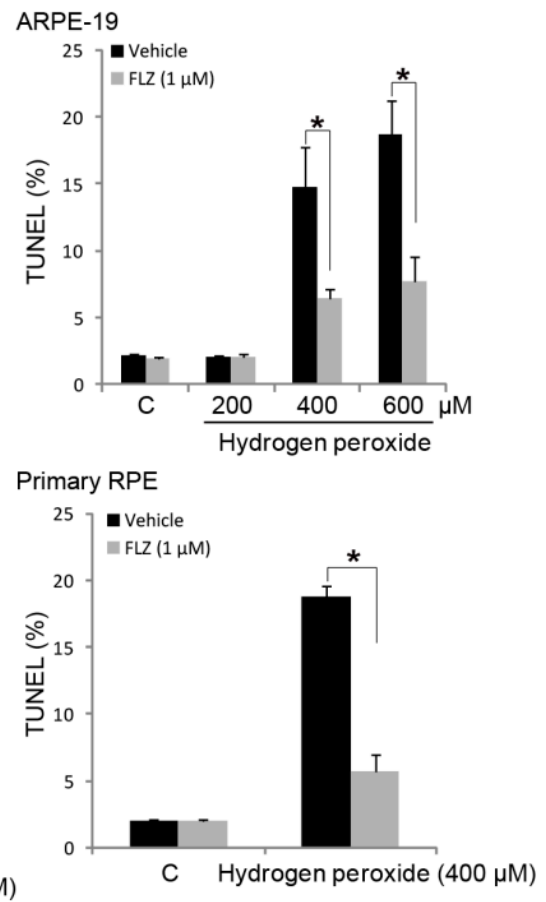

\subsection{FLZ Activates AKT in RPE Cells}

Next, we explored the mechanisms underlying the pro-survival effect of FLZ by focusing on AKT signaling. FLZ is shown to activate AKT in other cells [11], and AKT signaling is essential for the survival of RPE cells [18]. Western blotting results in Figure 3A,B demonstrated that FLZ induced AKT activation in both time- and dose-dependent manners. AKT activation was seen as early as two hours after FLZ treatment, and it lasted as least for six hours (Figure 3A). Further, as shown in Figure 3C, AKT was also activated by FLZ in primary RPE cells. Together, these results confirm AKT activation by FLZ in RPE cells. 
Figure 3. FLZ activates AKT in RPE cells. APRE-19 cells (A,B) and primary mouse RPE cells (C) were treated with FLZ for the indicated time, and phospho-(p-) AKT1 (Ser 473), regular AKT1 and $\beta$-actin were tested by western blotting. AKT1 phosphorylation was quantified. Experiments were repeated three times to insure consistency of results. "C" stands for the untreated control group. * $p<0.05$ vs. Group "C" (ANOVA).

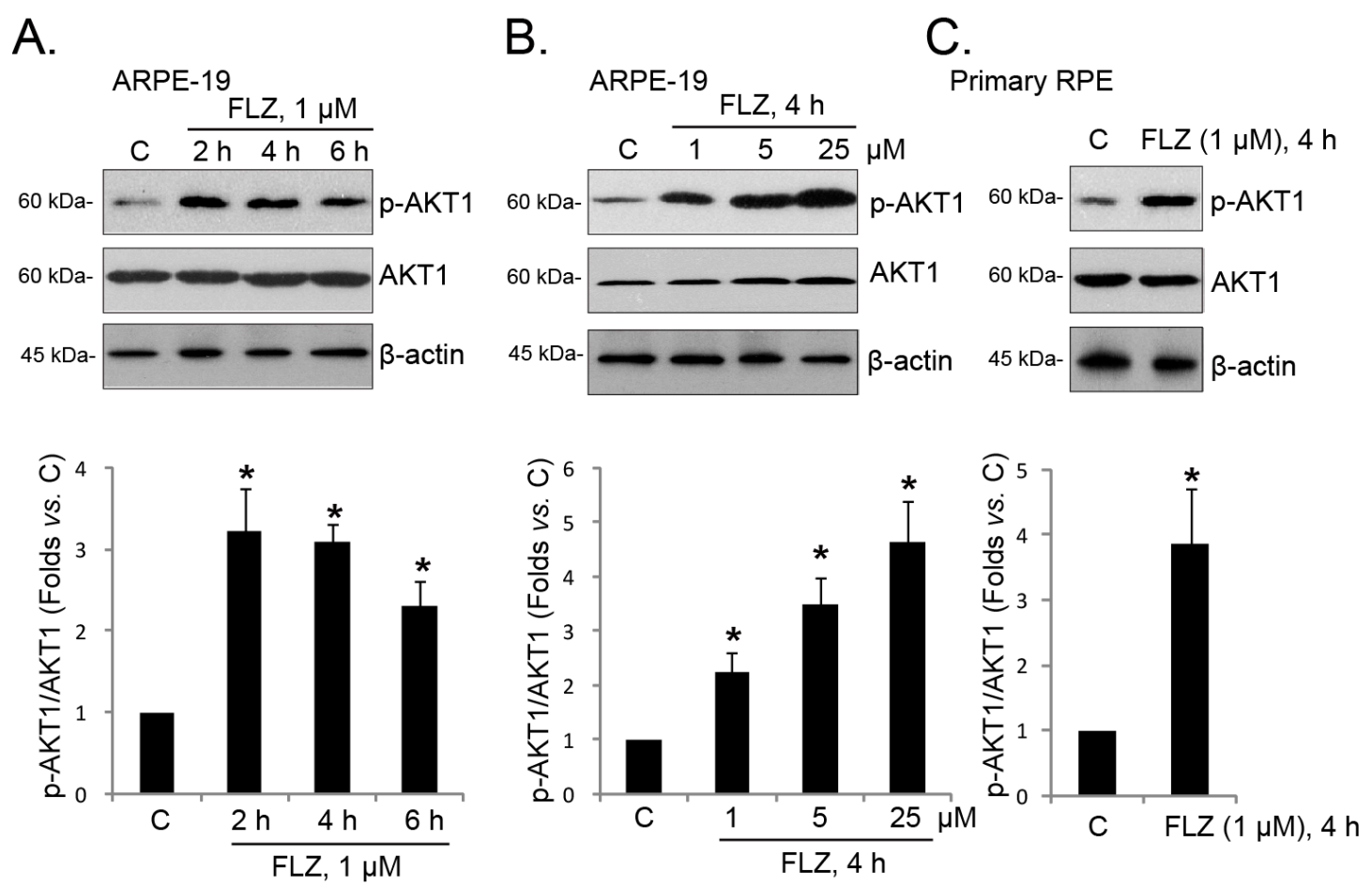

\subsection{AKT Activation Mediates the FLZ-Induced Pro-Survival Effect against $\mathrm{H}_{2} \mathrm{O}_{2}$}

Our group has shown that a number of agents, including NGF [6], ginsenoside Rg-1 [21], salvianolic acid $\mathrm{A}$ [8] and $\alpha-\mathrm{MSH}$ [9], induce the pro-survival effect in RPE cells, which is mediated, at least in part, by AKT activation. The results above have shown that FLZ activated AKT in RPE cells. Next, we explored the role of AKT activation in the pro-survival effect. As shown in Figure 4A,B, in APRE-19 cells, the AKT-specific inhibitor, MK-2206 (MK) [22,23], and the phosphoinositide 3-kinase (PI3K)/AKT pan inhibitor, wortmannin (WT) [24], largely inhibited the pro-survival and anti-apoptosis activities of FLZ against $\mathrm{H}_{2} \mathrm{O}_{2}$, indicating that AKT activation is required for FLZ's effect. To further support this hypothesis, we utilized targeted shRNA to selectively knockdown AKT1 in ARPE-19 cells (Figure 4C), and the results showed that FLZ-induced pro-survival and anti-apoptosis activities against $\mathrm{H}_{2} \mathrm{O}_{2}$ were diminished when AKT was depleted by shRNA (Figure 4D,E). Thus, AKT activation is important for the FLZ-mediated survival effect in RPE cells. 
Figure 4. AKT activation mediates the FLZ-induced pro-survival effect against $\mathrm{H}_{2} \mathrm{O}_{2}$. APRE-19 cells were treated with $\mathrm{H}_{2} \mathrm{O}_{2}(400 \mu \mathrm{M})$ or plus FLZ $(1 \mu \mathrm{M})$, in the presence of or absence of MK-2206 (MK, $5 \mu \mathrm{M}$ ) and wortmannin (WT, $5 \mu \mathrm{M}$ ) for $24 \mathrm{~h}$; cell viability was tested by the MTT assay (A); and cell apoptosis was tested by the TUNEL staining assay (B). The control APRE-19 cells (no shRNA infection) or stable APRE-19 cells infected with scramble-shRNA (sc shRNA) or AKT1-shRNA were treated with $\mathrm{H}_{2} \mathrm{O}_{2}$ $(400 \mu \mathrm{M})$ or plus FLZ $(1 \mu \mathrm{M})$ for $24 \mathrm{~h}$, cell viability was tested by the MTT assay (D), and apoptosis was tested by the TUNEL staining assay (E); FLZ $(1 \mu \mathrm{M})$-induced AKT1 phosphorylation was tested $(4 \mathrm{~h})$ and AKT1 phosphorylation and expression (vs. $\beta$-actin) were quantified $(\mathbf{C})$. Experiments were repeated three times to ensure the consistency of the results. "C" stands for the untreated control group. Vehicle stands for $0.1 \%$ DMSO. $* p<0.05$ (ANOVA).

A.

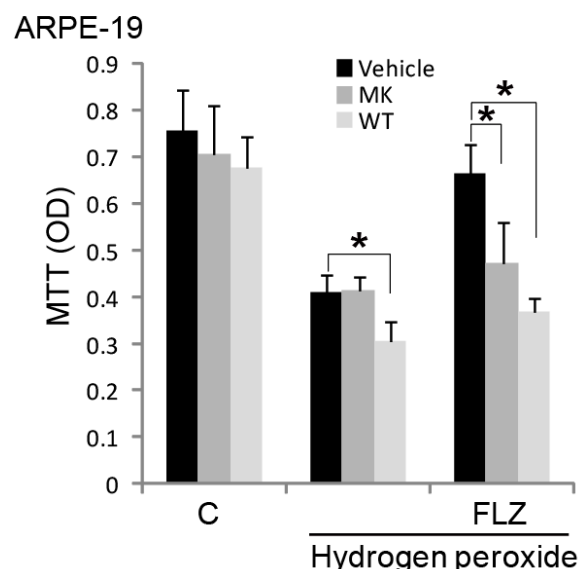

B.

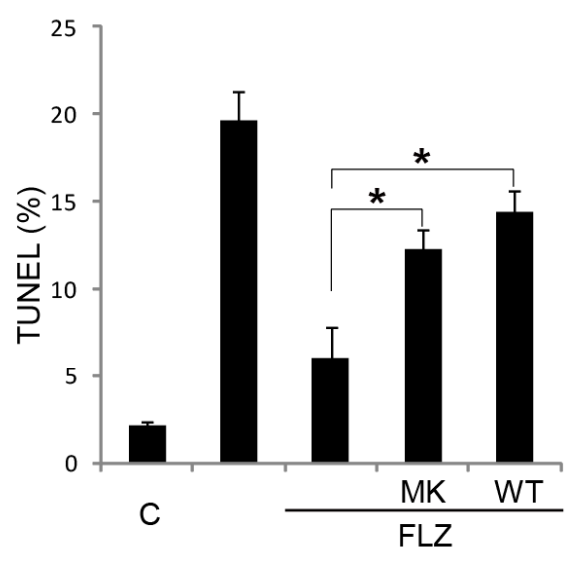

Hydrogen peroxide
C. ARPE-19

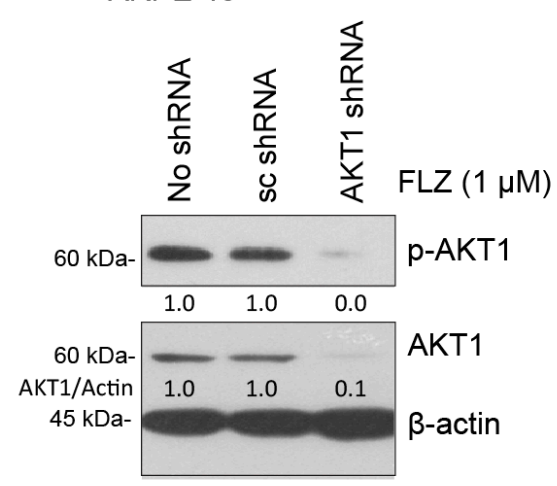

D.

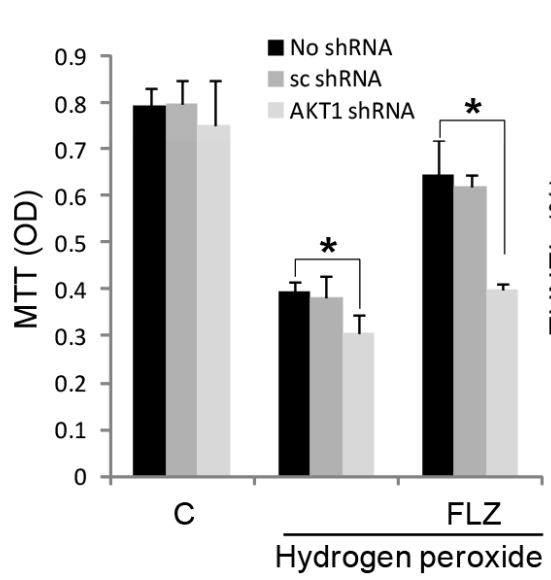

E.

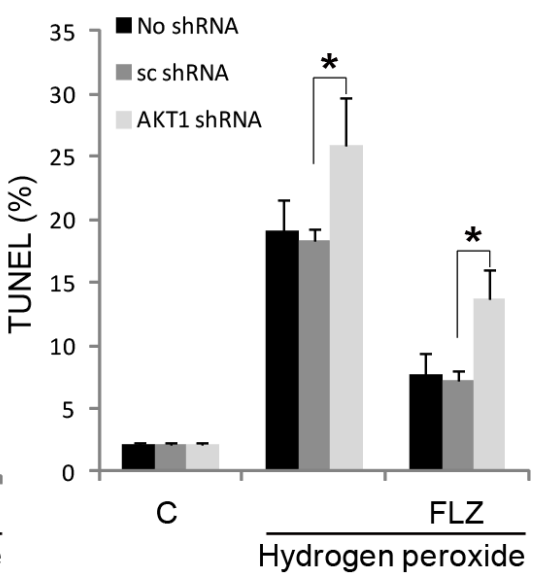

\subsection{EGFR (Epidermal Growth Factor Receptor) Trans-Activation Mediates FLZ-Induced AKT} Activation and Pro-Survival Effect in RPE Cells

Next, we studied the potential upstream signaling for AKT activation by FLZ in RPE cells. The EGF-EGFR signaling network is among one of the best-characterized signaling systems [25]. Besides being activated by its ligands, EGFR could also be activated indirectly by a number of agents, 
a process termed EGFR "trans-activation" [26-30]. Western blotting results in Figure 5A demonstrated that FLZ induced EGFR Tyr 1068 phosphorylation, the EGFR activation indicator, in cultured ARPE-19 cells, which was blocked by the EGFR inhibitor, PD153035 (PD) [31,32]. Meanwhile, PD153035 prevented FLZ-induced AKT activation (Figure 5A), indicating that EGFR trans-activation is required for FLZ-induced AKT activation. This is further supported by the fact that EGFR depletion by shRNA dramatically inhibited AKT activation by FLZ in APRE-19 cells (Figure 5C). $\mathrm{H}_{2} \mathrm{O}_{2}$ by itself could also slightly induce phosphorylation of EGFR and AKT in ARPE-19 cells, which was further increased by co-administration of FLZ (Figure 5B). Significantly, the EGFR inhibitor, PD153035, blocked EGFR-AKT phosphorylation by FLZ plus $\mathrm{H}_{2} \mathrm{O}_{2}$ (Figure $5 \mathrm{~A}, \mathrm{~B}$ ). These results suggest that trans-activation of EGFR and activation of its downstream signaling, AKT, are early events in $\mathrm{H}_{2} \mathrm{O}_{2}$-treated RPE cells (see the related reports [33-35]). FLZ increases AKT phosphorylation in $\mathrm{H}_{2} \mathrm{O}_{2}$-treated APRE-19 cells through enhancing EGFR activation. In APRE-19 cells, the pro-survival and anti-apoptosis activities of FLZ against $\mathrm{H}_{2} \mathrm{O}_{2}$ were alleviated by PD153035 or EGFR shRNA knockdown (Figure 5D,E). As shown in Figure 5F, in primary RPE cells, FLZ-induced pro-survival activity was similarly inhibited by PD153035 and wortmannin (WT). Together, we concluded that EGFR mediated FLZ-induced AKT activation and pro-survival activity in RPE cells (Figure 6).

Figure 5. EGFR (epidermal growth factor receptor) trans-activation mediates FLZ-induced AKT activation and the pro-survival effect in RPE cells. APRE-19 cells were pre-treated with EGFR inhibitor PD153035 (PD, $1 \mu \mathrm{M})$, followed by FLZ $(1 \mu \mathrm{M})$ stimulation in the presence or absence of $\mathrm{H}_{2} \mathrm{O}_{2}(400 \mu \mathrm{M})$; cells were further cultured for four hours, and EGFR, p-EGFR (Tyr 1068), AKT1 and p-AKT1 (Ser 473) were tested by western blotting (A,B); The control APRE-19 cells (no infection) or APRE-19 cells infected with scramble-shRNA or EGFR-shRNA lentiviral particles $(20 \mu \mathrm{L} / \mathrm{mL}, 24 \mathrm{~h}$ infection) were treated with FLZ $(1 \mu \mathrm{M})$ for $4 \mathrm{~h}$, and EGFR, AKT1 and p-AKT1 (Ser 473) were tested by western blotting (C); p-AKT1 was quantified. APRE-19 cells were treated with $\mathrm{H}_{2} \mathrm{O}_{2}(400 \mu \mathrm{M})$ or plus FLZ $(1 \mu \mathrm{M})$, in the presence or absence of PD153035 (PD, $1 \mu \mathrm{M})$ or EGFR-shRNA lentiviral particles ( $20 \mu \mathrm{L} / \mathrm{mL}, 24 \mathrm{~h}$ infection), and cells were further cultured for $24 \mathrm{~h}$. The MTT assay (D) and the TUNEL staining assay (E) were performed to test cell viability and apoptosis, respectively. Primary mouse RPE cells were treated with $\mathrm{H}_{2} \mathrm{O}_{2}(400 \mu \mathrm{M})$ or plus FLZ $(1 \mu \mathrm{M})$, in the presence or absence of PD153035 (PD, $1 \mu \mathrm{M})$ or wortmannin (WT, $5 \mu \mathrm{M})$; cell viability was tested by the MTT assay after $24 \mathrm{~h}(\mathbf{F})$. Experiments were repeated three times to ensure the consistency of the results. "C" stands for the untreated control group. $* p<0.05$ (ANOVA).

A.

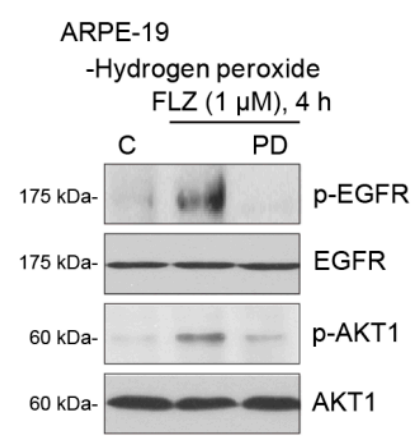

B.

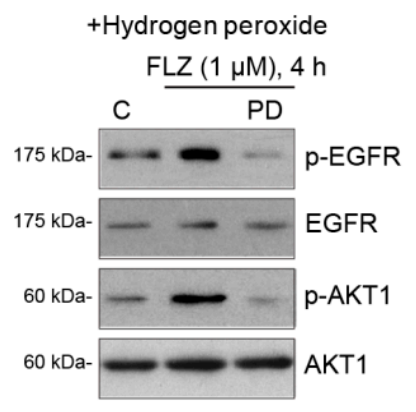

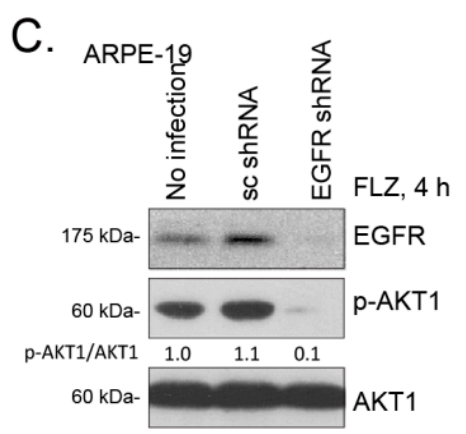


Figure 5. Cont.

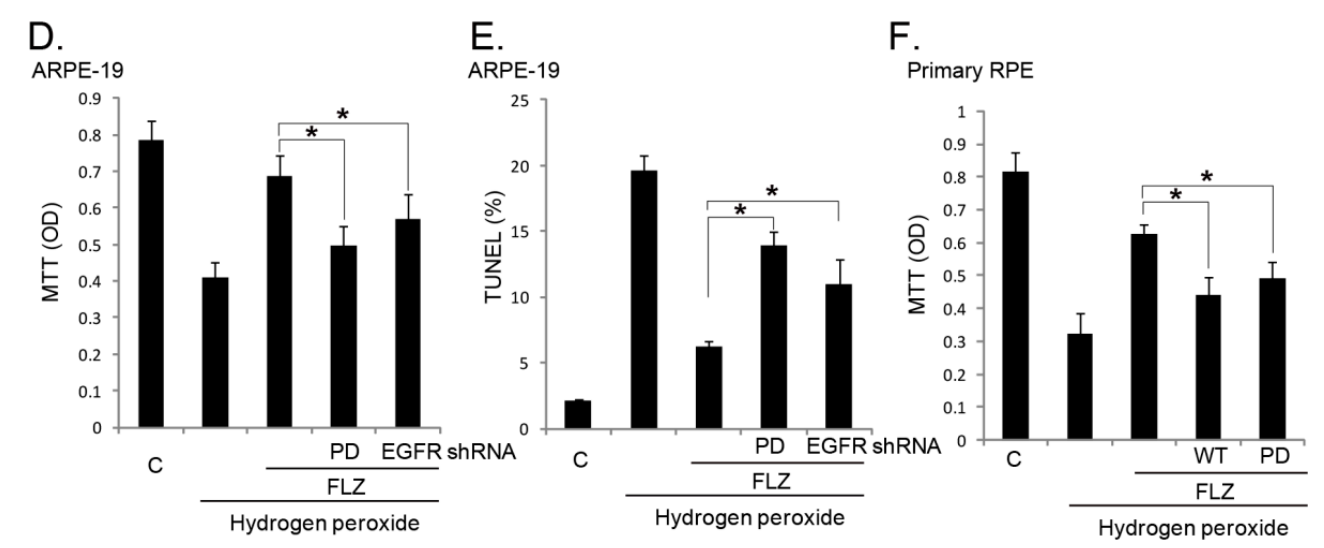

Figure 6. The proposed signaling pathway of this study.

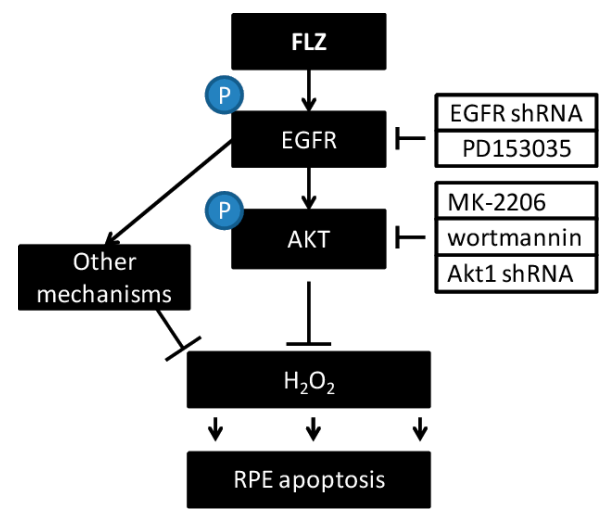

\subsection{Discussion}

The vision loss among elderly AMD patients starts from abnormalities in the RPE, along with photoreceptor damage, Bruch's membrane thickening and choriocapillary hypo-perfusion [36]. These are considered as the main characteristics of AMD [37]. UV radiation and subsequent oxidative stress damage are known as the main contributors to AMD [38-43]. In the current study, we showed that FLZ activated EGFR-AKT signaling and attenuated $\mathrm{H}_{2} \mathrm{O}_{2}$-induced RPE cell death and apoptosis. These effects by FLZ were inhibited by AKT/EGFR inhibition or depletion. Thus, we suggest that FLZ prevents $\mathrm{H}_{2} \mathrm{O}_{2}$-induced RPE cell damage through activating EGFR-AKT signaling (Figure 6).

EGFR is functionally expressed in RPE cells [44-46]. EGFR and their ligands modulate cellular functions in a variety of ways, including proliferation, survival, adhesion, migration and apoptosis resistance [47]. The EGFR ligands, including EGF, amphiregulin and transforming growth factor alpha (TGF $\alpha$ ), as well as and heparin binding EGF (HB-EGF) and epiregulin directly bind to and activate EGFR [47]. Activated EGFR recruits adaptor proteins to activate downstream signaling molecules (i.e., AKT signaling) [48] and to promote cell survival [47]. EGFR could also be trans-activated indirectly by various stimuli [26-30]. In the current study, we found that FLZ-induced AKT activation was also mediated through EGFR trans-activation. The conclusion was supported by the fact that EGFR inhibitor or silencing inhibited AKT activation by FLZ. Meanwhile, the pro-survival activity of FLZ against $\mathrm{H}_{2} \mathrm{O}_{2}$ was also attenuated by EGFR inhibitor or depletion. Thus, EGFR trans-activation is the upstream signal for FLZ-induced AKT activation, which promotes RPE cell survival (Figure 6). 


\section{Experimental Section}

\subsection{Chemical and Reagents}

FLZ is a white powder with $99 \%$ purity and is insoluble in water [16]. FLZ was synthesized by Wuxi Ya-tai Bio Company (Wuxi, China) based on the structure described in [16]. FLZ was dissolved in dimethyl sulfoxide (DMSO) and added to the cell culture medium with a maximum DMSO concentration of $0.1 \%$. PD153035, MK-2206 and wortmannin were purchased from Calbiochem (Darmstadt, Germany). The antibody against $\beta$-actin was purchased from Sigma (St. Louis, MO, USA). All other antibodies used in this study were obtained from Cell Signaling Tech (Danvers, MA, USA).

\subsection{APRE-19 Cell Culture}

As reported [7], the human retinal pigment epithelial cell line (ARPE-19) was routinely maintained in Dulbecco's modified Eagle's medium (DMEM)/Nutrient Mixture F-12 (DMEM/F12, Gibco, Carlsbad, CA, USA) containing 10\% fetal bovine serum (FBS) (Hyclone, Shanghai, China), penicillin/streptomycin (1:100, Sigma, St. Louis, MO, USA) and $4 \mathrm{mM} \mathrm{L-glutamine} \mathrm{and} \mathrm{0.19 \%}$ HEPES (hydroxyethyl piperazineethanesulfonic acid, Sigma), in a humidified incubator at $37{ }^{\circ} \mathrm{C}$ and $5 \% \mathrm{CO}_{2}$.

\subsection{Primary Mouse RPE Cell Isolation and Culture}

As reported [7,9], C57/B6 mice at the age of 3-5 days were given anesthesia by 75\% alcohol, and the eyeballs in asepsis were taken out and diluted several times with D-hank's fluid. After soaking in the DMEM/F-12 for $6 \mathrm{~h}$, the eyeballs were taken out, and the retinas were striped carefully. Parenzyme $(0.125 \%)$ was added to digest for $20 \mathrm{~min}$ at $37^{\circ} \mathrm{C}$ before adding culture medium containing blood serum to terminate digestion. Then, the supernatant was centrifuged twice at $1000 \mathrm{r} / \mathrm{min}$ in the culture medium (80\% DMEM/F-12, 20\% FBS) to produce a cell suspension after inoculation into the $75-\mathrm{cm}^{2}$ culture flask. Cells were divided and were used for the designed experiments. For all experiments, RPE cells (primary and ARPE-19 cells) were serum-starved overnight using serum-free DMEM medium, and the next day, FLZ and inhibitors were added to the cells.

\subsection{Cell Viability Assay}

Cell viability was assessed by the 3-[4,5-dimethylthylthiazol-2-yl]-2,5 diphenyltetrazolium bromide (MTT) (Sigma, Shanghai, China) assay. In brief, RPE cells were collected and seeded in 96-well plates at a density of $1 \times 10^{5}$ cells/well in $200 \mathrm{~mL}$ of culture medium. After treatment, $20 \mu \mathrm{L}$ of MTT solution $(5 \mathrm{mg} / \mathrm{mL})$ were added to each well for $4 \mathrm{~h}$ at $37^{\circ} \mathrm{C}$, and cell viability was determined by measuring absorbance at $490 \mathrm{~nm}$ using a microplate spectrophotometer (Molecular Devices, Sunnyvale, CA, USA). The OD value was detected as an indicator of RPE cell viability.

\subsection{Western Blotting}

As reported [7,9], aliquots of $20 \mu \mathrm{g}$ of proteins (lysed by $40 \mathrm{mM}$ HEPES (pH 7.5), $120 \mathrm{mM} \mathrm{NaCl}$, $1 \mathrm{mM}$ EDTA (Ethylene Diamine Tetraacetic Acid), $10 \mathrm{mM}$ pyrophosphate, $10 \mathrm{mM}$ glycerophosphate, 
$50 \mathrm{mM} \mathrm{NaF}, 0.5 \mathrm{mM}$ orthovanadate, EDTA-free protease inhibitors (Roche, Shanghai, China) and $1 \%$ Triton) were separated by $10 \%$ SDS (sodium dodecyl sulfate) polyacrylamide gel electrophoresis (SDS-PAGE) and transferred onto polyvinylidene difluoride (PVDF) membranes (Millipore, Bedford, MA, USA). After blocking with $10 \%$ non-fat dry milk for $1 \mathrm{~h}$, membranes were incubated with the described antibodies overnight at $4{ }^{\circ} \mathrm{C}$, followed by incubation with secondary antibodies for one hour at room temperature. The blots were visualized with enhanced chemiluminescence (ECL). Band intensities in the immunoblots were quantified by densitometry using ImageJ software (NIH, Bethesda, MD, USA). Phospho-kinases were always normalized to non-phospho-controls [7].

\subsection{Annexin-V/PI FACS (Fluorescence-Activated Cell Sorting) Assay}

RPE cell apoptosis was measured by Annexin-V fluorescence-activated cell sorting (FACS) according to the manufacturer's protocol (Sigma). Briefly, after treatment, cells were washed twice with cold PBS (phosphate buffer solution) and incubated in $300 \mu \mathrm{L}$ binding buffer containing $3 \mu \mathrm{L}$ of Annexin-V-FITC (fluorescein isothiocyanate) and $3 \mu \mathrm{L}$ of propidium iodine (PI) in the dark for $15 \mathrm{~min}$ at room temperature. The stained samples (containing 200,000 cell/sample) were then analyzed on a FACSCalibur flow cytometer within $1 \mathrm{~h}$ following the manufacturer's protocol (Coulter, Hialeah, FL, USA). Annexin-V percentage was recorded as an indicator of apoptosis intensity; while Annexin- $V^{-1}$ and $\mathrm{PI}^{+/+}$cells were labeled as necrotic cells. All experiments were performed in triplicate.

\subsection{TUNEL (Terminal Deoxynucleotidyl Transferase dUTP Nick End Labeling) Staining}

RPE cell apoptosis was detected by the TUNEL. In Situ Cell Death Detection Kit (Roche Molecular Biochemicals, Indianapolis, IN, USA), according to the manufacturer's instructions. RPE cells were also stained with 4',6'-diamino-2-phenylin-dole (DAPI, blue fluorescence; Molecular Probes) to visualize the cell nuclei. The apoptosis rate was determined by TUNEL percentage, which was calculated by the number of TUNEL-positive cells divided by the number of DAPI-stained cells. At least 1000 total cells in 10 views from 10 repeat wells $(1 \times 100)$ of each condition were included for counting the TUNEL percentage.

\subsection{Stable AKT1 Knockdown by Short Hairpin RNA (shRNA)}

The lentiviral particles containing scramble shRNA or AKT1 shRNA were synthesized, verified and provided by Kaiji Biotech (Shanghai, China). The hairpin sequences used for AKT1 were as follows: forward, 5'-CCGGTGCTGCTTCCTCCTCAAGAATGTTCAAGAGACATTCTTGAGGA GGAAGTAGCTTTTTGGAAG-3'; reverse, 5'-AATTCTTCCAAAAAGCTACTTCCTCCTCAAGAA TGTCTCTTGAACATTCTTGAGGAGGAAGCAGCA-3'. The lentiviral shRNA $(20 \mu \mathrm{L} / \mathrm{mL})$ was added to ARPE-19 cells for $24 \mathrm{~h}$, and stable clones expressing shRNA were further selected by puromycin $(1.0 \mu \mathrm{g} / \mathrm{mL})$. Cell culture medium containing puromycin was renewed every $48 \mathrm{~h}$, until resistant colonies could be identified (4-5 passages). The expression of AKT1 and the loading control $(\beta$-actin) in stable cells was tested. 


\subsection{Transit Knockdown of Epidermal Growth Factor Receptor (EGFR) by shRNA}

The lentiviral particles containing scramble shRNA (sc-108080) or human EGFR shRNA (sc-29301-V) were purchased from Santa Cruz Biotech (Santa Cruz, CA, USA). Lentiviral shRNA particles $(20 \mu \mathrm{L} / \mathrm{mL})$ were added to the ARPE-19 cells for $24 \mathrm{~h}$, and the expression level of EGFR and the loading control in infected cells were tested.

\subsection{Statistical Analysis}

All data were presented as the mean \pm standard deviation (SD). Statistics were analyzed by one-way ANOVA followed by a Scheffe's $f$-test by using SPSS 17.0 software (SPSS Inc., Chicago, IL, USA). Significance was chosen as $p<0.05$.

\section{Conclusions}

FLZ prevents $\mathrm{H}_{2} \mathrm{O}_{2}$-induced RPE cell apoptosis through activating EGFR-AKT signaling. Since AMD is characterized by a progressive decay of RPE cells at the posterior pole of the eye and ROS are the major contributors of RPE damages in AMD, our results suggest that FLZ might have therapeutic value for AMD.

\section{Acknowledgments}

This work was generously supported by grants from the National Natural Science Foundation of China.

\section{Author Contributions}

Li-Bo Cheng, Li-Juan Zhu and Chun-Ming Chen conceived the idea, design of the work, and wrote the paper and the correspondences. Li-Bo Cheng, Li-Juan Zhu, Hong Zhong and Chun-Ming Chen performed the experiments.

\section{Conflicts of Interest}

The authors declare no conflict of interest.

\section{References}

1. Friedman, D.S.; O’Colmain, B.J.; Munoz, B.; Tomany, S.C.; McCarty, C.; de Jong, P.T.; Nemesure, B.; Mitchell, P.; Kempen, J. Prevalence of age-related macular degeneration in the United States. Arch. Ophthalmol. 2004, 122, 564-572.

2. Chen, Y.; Gibson, S.B. Is mitochondrial generation of reactive oxygen species a trigger for autophagy? Autophagy 2008, 4, 246-248.

3. Pacifici, R.E.; Davies, K.J. Protein, lipid and DNA repair systems in oxidative stress: The free-radical theory of aging revisited. Gerontology 1991, 37, 166-180. 
4. Bartlett, H.; Eperjesi, F. A randomised controlled trial investigating the effect of nutritional supplementation on visual function in normal, and age-related macular disease affected eyes: Design and methodology [ISRCTN78467674]. Nutr. J. 2003, 2, doi:10.1186/1475-2891-2-12.

5. Richer, S.; Stiles, W.; Statkute, L.; Pulido, J.; Frankowski, J.; Rudy, D.; Pei, K.; Tsipursky, M.; Nyland, J. Double-masked, placebo-controlled, randomized trial of lutein and antioxidant supplementation in the intervention of atrophic age-related macular degeneration: The Veterans LAST study (Lutein Antioxidant Supplementation Trial). Optometry 2004, 75, 216-230.

6. Cao, G.F.; Liu, Y.; Yang, W.; Wan, J.; Yao, J.; Wan, Y.; Jiang, Q. Rapamycin sensitive mTOR activation mediates nerve growth factor (NGF) induced cell migration and pro-survival effects against hydrogen peroxide in retinal pigment epithelial cells. Biochem. Biophys. Res. Commun. 2011, 414, 499-505.

7. Yao, J.; Bi, H.E.; Sheng, Y.; Cheng, L.B.; Wendu, R.L.; Wang, C.H.; Cao, G.F.; Jiang, Q. Ultraviolet (UV) and hydrogen peroxide activate ceramide-ER stress-AMPK signaling axis to promote retinal pigment epithelium (RPE) cell apoptosis. Int. J. Mol. Sci. 2013, 14, 10355-10368.

8. Zhang, H.; Liu, Y.Y.; Jiang, Q.; Li, K.R.; Zhao, Y.X.; Cao, C.; Yao, J. Salvianolic acid A protects RPE cells against oxidative stress through activation of Nrf2/HO-1 signaling. Free Radic. Biol. Med. 2014, 69, 219-228.

9. Cheng, L.B.; Cheng, L.; Bi, H.E.; Zhang, Z.Q.; Yao, J.; Zhou, X.Z.; Jiang, Q. Alpha-melanocyte stimulating hormone protects retinal pigment epithelium cells from oxidative stress through activation of melanocortin 1 receptor-Akt-mTOR signaling. Biochem. Biophys. Res. Commun. 2014, 443, 447-452.

10. Chen, S.H.; Li, D.L.; Yang, F.; Wu, Z.; Zhao, Y.Y.; Jiang, Y. Gemcitabine-induced pancreatic cancer cell death is associated with MST1/Cyclophilin D mitochondrial complexation. Biochimie 2014, 103, 71-79.

11. Bao, X.Q.; Kong, X.C.; Kong, L.B.; Wu, L.Y.; Sun, H.; Zhang, D. Squamosamide derivative FLZ protected dopaminergic neuron by activating Akt signaling pathway in 6-OHDA-induced in vivo and in vitro Parkinson's disease models. Brain Res. 2014, 1547, 49-57.

12. Bao, X.Q.; Li, N.; Wang, T.; Kong, X.C.; Tai, W.J.; Sun, H.; Zhang, D. FLZ alleviates the memory deficits in transgenic mouse model of Alzheimer's disease via decreasing beta-amyloid production and tau hyperphosphorylation. PLoS One 2013, 8, e78033.

13. Bao, X.Q.; Kong, X.C.; Qian, C.; Zhang, D. FLZ protects dopaminergic neuron through activating protein kinase B/mammalian target of rapamycin pathway and inhibiting RTP801 expression in Parkinson's disease models. Neuroscience 2012, 202, 396-404.

14. Fang, F.; Liu, G.T. Novel squamosamide derivative (compound FLZ) attenuates A $\beta 25-35$-induced toxicity in SH-SY5Y cells. Acta Pharmacol. Sin. 2008, 29, 152-160.

15. Kong, X.C.; Zhang, D.; Qian, C.; Liu, G.T.; Bao, X.Q. FLZ, a novel HSP27 and HSP70 inducer, protects SH-SY5Y cells from apoptosis caused by MPP(+). Brain Res. 2011, 1383, 99-107.

16. Zhang, D.; Zhang, J.J.; Liu, G.T. The novel squamosamide derivative FLZ protects against 6-hydroxydopamine-induced apoptosis through inhibition of related signal transduction in SH-SY5Y cells. Eur. J. Pharmacol. 2007, 561, 1-6.

17. Kang, R.X.; Zhang, J.J. A natural squamosamide derivative FLZ inhibits homocysteine-induced rat brain microvascular endothelial cells dysfunction. Biochem. Biophys. Res. Commun. 2012, 417, 1176-1181. 
18. Song, G.; Ouyang, G.; Bao, S. The activation of Akt/PKB signaling pathway and cell survival. J. Cell Mol. Med. 2005, 9, 59-71.

19. Vivanco, I.; Sawyers, C.L. The phosphatidylinositol 3-Kinase AKT pathway in human cancer. Nat. Rev. Cancer 2002, 2, 489-501.

20. Hennessy, B.T.; Smith, D.L.; Ram, P.T.; Lu, Y.; Mills, G.B. Exploiting the PI3K/AKT pathway for cancer drug discovery. Nat. Rev. Drug Discov. 2005, 4, 988-1004.

21. Li, K.R.; Zhang, Z.Q.; Yao, J.; Zhao, Y.X.; Duan, J.; Cao, C.; Jiang, Q. Ginsenoside Rg-1 protects retinal pigment epithelium (RPE) cells from cobalt chloride $(\mathrm{CoCl} 2)$ and hypoxia assaults. PLoS One 2013, 8, e84171.

22. Ji, D.; Zhang, Z.; Cheng, L.; Chang, J.; Wang, S.; Zheng, B.; Zheng, R.; Sun, Z.; Wang, C.; Liu, R.; et al. The combination of RAD001 and MK-2206 exerts synergistic cytotoxic effects against PTEN mutant gastric cancer cells: Involvement of MAPK-dependent autophagic, but not apoptotic cell death pathway. PLoS One 2014, 9, e85116.

23. Yap, T.A.; Yan, L.; Patnaik, A.; Fearen, I.; Olmos, D.; Papadopoulos, K.; Baird, R.D.; Delgado, L.; Taylor, A.; Lupinacci, L.; et al. First-in-man clinical trial of the oral pan-AKT inhibitor MK-2206 in patients with advanced solid tumors. J. Clin. Oncol. 2011, 29, 4688-4695.

24. Brunn, G.J.; Williams, J.; Sabers, C.; Wiederrecht, G.; Lawrence, J.C., Jr.; Abraham, R.T. Direct inhibition of the signaling functions of the mammalian target of rapamycin by the phosphoinositide 3-kinase inhibitors, wortmannin and LY294002. EMBO J. 1996, 15, 5256-5267.

25. Tomas, A.; Futter, C.E.; Eden, E.R. EGF receptor trafficking: Consequences for signaling and cancer. Trends Cell Biol. 2014, 24, 26-34.

26. Cao, C.; Lu, S.; Jiang, Q.; Wang, W.J.; Song, X.; Kivlin, R.; Wallin, B.; Bagdasarian, A.; Tamakloe, T.; Chu, W.M.; et al. EGFR activation confers protections against UV-induced apoptosis in cultured mouse skin dendritic cells. Cell Signal. 2008, 20, 1830-1838.

27. Maretzky, T.; Evers, A.; Zhou, W.; Swendeman, S.L.; Wong, P.M.; Rafii, S.; Reiss, K.; Blobel, C.P. Migration of growth factor-stimulated epithelial and endothelial cells depends on EGFR transactivation by ADAM17. Nat. Commun. 2011, 2, doi:10.1038/ncomms1232.

28. Oganesian, A.; Yarov-Yarovoy, V.; Parks, W.C.; Schwinn, D.A. Constitutive coupling of a naturally occurring human alphala-adrenergic receptor genetic variant to EGFR transactivation pathway. Proc. Natl. Acad. Sci. USA 2011, 108, 19796-19801.

29. Sur, S.; Agrawal, D.K. Transactivation of EGFR by G protein-coupled Receptor in the Pathophysiology of Intimal Hyperplasia. Curr. Vasc. Pharmacol. 2014, 12, 190-201.

30. McElroy, S.J.; Hobbs, S.; Kallen, M.; Tejera, N.; Rosen, M.J.; Grishin, A.; Matta, P.; Schneider, C.; Upperman, J.; Ford, H.; et al. Transactivation of EGFR by LPS induces COX-2 expression in enterocytes. PLoS One 2012, 7, e38373.

31. Cao, C.; Sun, Y.; Healey, S.; Bi, Z.; Hu, G.; Wan, S.; Kouttab, N.; Chu, W.; Wan, Y. EGFR-mediated expression of aquaporin-3 is involved in human skin fibroblast migration. Biochem. J. 2006, 400, 225-234.

32. Qiu, L.; Zhou, C.; Sun, Y.; Di, W.; Scheffler, E.; Healey, S.; Wanebo, H.; Kouttab, N.; Chu, W.; Wan, Y. Paclitaxel and ceramide synergistically induce cell death with transient activation of EGFR and ERK pathway in pancreatic cancer cells. Oncol. Rep. 2006, 16, 907-913. 
33. Niwa, K.; Inanami, O.; Yamamori, T.; Ohta, T.; Hamasu, T.; Kuwabara, M. Redox regulation of PI3K/Akt and p53 in bovine aortic endothelial cells exposed to hydrogen peroxide. Antioxid. Redox Signal. 2003, 5, 713-722.

34. Chen, K.; Thomas, S. R.; Albano, A.; Murphy, M. P.; Keaney, J. F., Jr. Mitochondrial function is required for hydrogen peroxide-induced growth factor receptor transactivation and downstream signaling. J. Biol. Chem. 2004, 279, 35079-35086.

35. Radisavljevic, Z.M.; Gonzalez-Flecha, B. TOR kinase and Ran are downstream from PI3K/Akt in H2O2-induced mitosis. J. Cell Biochem. 2004, 91, 1293-1300.

36. Young, R.W. Pathophysiology of age-related macular degeneration. Surv. Ophthalmol. 1987, 31, 291-306.

37. Zarbin, M. Age-related macular degeneration: Review of pathogenesis. Eur. J. Ophthalmol. 1998, 8, 199-206.

38. Roduit, R.; Schorderet, D.F. MAP kinase pathways in UV-induced apoptosis of retinal pigment epithelium ARPE19 cells. Apoptosis 2008, 13, 343-353.

39. Liang, Y.G.; Jorgensen, A.G.; Kaestel, C.G.; Wiencke, A.K.; Lui, G.M.; la Cour, M.H.; Ropke, C.H.; Nissen, M.H. Bcl-2, Bax, and c-Fos expression correlates to RPE cell apoptosis induced by UV-light and daunorubicin. Curr. Eye Res. 2000, 20, 25-34.

40. Nilsson, S.E.; Sundelin, S.P.; Wihlmark, U.; Brunk, U.T. Aging of cultured retinal pigment epithelial cells: Oxidative reactions, lipofuscin formation and blue light damage. Doc. Ophthal. Mol. 2003, 106, 13-16.

41. Drobek-Slowik, M.; Karczewicz, D.; Safranow, K. The potential role of oxidative stress in the pathogenesis of the age-related macular degeneration (AMD) (in Polish). Postepy Hig. Med. Dosw. Online 2007, 61, 28-37.

42. Nowak, M.; Gnitecki, W.; Jurowski, P. The role of retinal oxygen metabolism in origin of age-related macular degeneration (AMD) (in Polish). Klin. Oczna 2005, 107, 715-718.

43. King, A.; Gottlieb, E.; Brooks, D.G.; Murphy, M.P.; Dunaief, J.L. Mitochondria-derived reactive oxygen species mediate blue light-induced death of retinal pigment epithelial cells. Photochem. Photobiol. 2004, 79, 470-475.

44. Xu, K.P.; Yu, F.S. Cross talk between c-Met and epidermal growth factor receptor during retinal pigment epithelial wound healing. Investig. Ophthal. Mol. Vis. Sci. 2007, 48, 2242-2248.

45. Yan, F.; Hui, Y.N.; Li, Y.J.; Guo, C.M.; Meng, H. Epidermal growth factor receptor in cultured human retinal pigment epithelial cells. Ophthalmologica 2007, 221, 244-250.

46. Zhang, L.; Wang, F.; Jiang, Y.; Xu, S.; Lu, F.; Wang, W.; Sun, X. Migration of retinal pigment epithelial cells is EGFR/PI3K/AKT dependent. Front. BioSci. Schol. Ed. 2013, 5, 661-671.

47. Herbst, R.S. Review of epidermal growth factor receptor biology. Int. J. Radiat. Oncol. Biol. Phys. 2004, 59, 21-26.

48. Cao, C.; Huang, X.; Han, Y.; Wan, Y.; Birnbaumer, L.; Feng, G.S.; Marshall, J.; Jiang, M.; Chu, W.M. Galpha(i1) and Galpha(i3) are required for epidermal growth factor-mediated activation of the Akt-mTORC1 pathway. Sci. Signal 2009, 2, doi:10.1126/scisignal.2000118.

(C) 2014 by the authors; licensee MDPI, Basel, Switzerland. This article is an open access article distributed under the terms and conditions of the Creative Commons Attribution license (http://creativecommons.org/licenses/by/4.0/). 